\title{
STABILITY OF THE SCOLIOTIC SPINE AFTER FUSION
}

\author{
MICHAEL J. McMASTER
}

From the Edinburgh Scoliosis Unit, Princess Margaret Rose Orthopaedic Hospital, Edinburgh

\begin{abstract}
The factors during and after operation which influence the development of a solid and stable posterior spinal fusion have been evaluated in $\mathbf{4 0 6}$ patients with scoliosis. The patients were managed in three different ways and all pseudarthroses were accurately detected by exploring the spines six months after the attempted fusion. The incidence of pseudarthroses was significantly lowered from 25 per cent in Group I to 3.8 per cent in Group III by the application of Harrington instrumentation and the use of large amounts of autogenous iliac bone grafts in addition to an interfacetal fusion. Early mobilisation $\mathbf{7}$ to $\mathbf{1 0}$ days after operation and a return to normal activities in a well-moulded underarm plaster jacket did not have a detrimental effect on the development of the fusion or the early maintenance of correction. Those spines with supplementary bone grafts stabilised more rapidly and had better maintenance of correction with only minimal loss after removal of all external support at 10 months.
\end{abstract}

The stability of the scoliotic spine after fusion depends on producing a solid fusion of sufficient strength to resist bending under the influence of gravity and the deforming factors which first caused the curvature. Correction may be lost due either to the development of a pseudarthrosis or to bending of a solid but weak fusion. Serial spinal radiographs, measured using Cobb's technique (1948), are an excellent means of showing deterioration of the curve but are not always capable of distinguishing between a pseudarthrosis and bending of a solid fusion. Cobb (1952) stated that the only way to be absolutely accurate in the study of spinal fusions was to explore each spine surgically. Only a relatively few surgeons have done this routinely but all have found a much higher incidence of pseudarthroses than were apparent radiographically (Outland, McDowell and Flynn 1964; May and Mauck 1966; Ashley 1967; Graham 1968; Donaldson, Wissinger and Stone 1969; Mathews and Stelling 1970; McMaster and James 1976).

The purpose of this paper is to investigate the important operative and postoperative factors influencing the development of a solid and stable spinal fusion in patients with scoliosis. Three groups of patients treated by posterior spinal fusion but managed in different ways are compared, with special attention being given to the effects of Harrington instrumentation, the use of supplementary autogenous bone grafts and early mobilisation in a simple underarm cast. In order accurately to detect all pseudarthroses the spines were surgically explored six months after the attempted fusion. It was then possible to study radiographically the factors influencing the stability of the solid fusion.

\section{CLINICAL MATERIAL}

At the Princess Margaret Rose Orthopaedic Hospital, Edinburgh, during the period 1962 to 1977,406 consecutive patients with scoliosis of the idiopathic, congenital and paralytic varieties have had a posterior spinal fusion followed by an exploration six months later. This second operation was carried out, as advocated by James (1965), to detect and repair pseudarthroses at an early stage and so prevent subsequent loss in correction.

The 222 patients with scoliosis operated on before 1973 have been studied retrospectively by reviewing their case notes and spinal radiographs taken before operation and during the follow-up period. The majority of these patients had their scoliosis corrected by the application of a Risser localiser jacket without Harrington instrumentation and have been the subject of a preliminary investigation into the incidence of pseudarthroses (McMaster and James 1976). Nearly all of these patients have now been followed to skeletal maturity and are used as a control group with which to compare the results obtained in the prospective study.

Since 1973 I have carried out a prospective study on a further 184 patients with scoliosis who have had a posterior spinal fusion followed by an exploration six months later. The majority of these patients were operated on by myself and had their scoliosis corrected using Harrington instrumentation with a specific attempt being made to lower the incidence of pseudarthrosis by modifying the fusion technique and the postoperative management.

Of the total number of patients 284 were girls and 122 boys, whose ages at spinal fusion ranged from 7 to 28 years (mean 12 years 5 months). The aetiology of the scoliosis in 239 patients was idiopathic, 98 were congenital and 69 neuropathic. Three hundred and eighty-four patients had a single structural curve of which 303 were thoracic, 78 thoracolumbar and three lumbar. There were 22 patients with a double structural scoliosis of which five were double thoracic and 17 had combined thoracic and lumbar curves.

\section{METHODS}

The patients fell naturally into three study groups, each group representing a step in the evolution of either the method of correction, technique of posterior spinal fusion or postoperative management (Tables I and II). 
Group I (243 patients). The scoliosis was corrected using a Risser localiser jacket followed one week later by a posterior spinal fusion through a large window cut in the back of the cast. No internal fixation was used and the spine was fused using only the interfacetal, intertransverse fusion technique described by Moe (1958). In this method of fusion the interfacetal joints are excised by turning back leaves of bone to come into contact in the intertransverse spaces. Small carefully shaped blocks of corticocancellous bone are then punched into the excised joints. The posterior elements were not decorticated nor were supplementary onlay bone grafts used. After operation the patient was kept in bed for one to three months before being allowed home in the Risser jacket which was not changed until exploration. Activities until exploration were confined to the house and garden.

Table I. Method of correction and technique of fusion

\begin{tabular}{|l|l|l|}
\hline Group II & $\begin{array}{c}\text { Method of } \\
\text { correction }\end{array}$ & $\begin{array}{l}\text { Technique of fusion } \\
\text { jacket }\end{array}$ \\
\hline Grocaliser & $\begin{array}{l}\text { A Moe interfacetal, intertransverse } \\
\text { instrumentation } \\
\text { fusion alone } \\
\text { A Moe interfacetal, intertransverse } \\
\text { fusion alone } \\
\text { Harrington } \\
\text { instrumentation }\end{array}$ & $\begin{array}{l}\text { A Moe interfacetal intertransverse } \\
\text { fusion plus decortication of all } \\
\text { posterior spinal structures and an } \\
\text { onlay of autogenous iliac bone } \\
\text { grafts }\end{array}$ \\
\hline
\end{tabular}

Group II (57 patients). The scoliosis was corrected using the Harrington distraction system. In 30 patients preliminary correction was obtained by means of a Risser localiser jacket applied one week before operation. As in Group I the spines were fused using the Moe (1958) interfacetal, intertransverse fusion technique without decorticating the posterior elements or adding supplementary onlay bone grafts. Immediately after operation anterior and posterior plaster shells were applied and maintained for two weeks. Then a simple

Table II. Postoperative management

\begin{tabular}{|c|c|c|c|c|}
\hline & \multicolumn{2}{|c|}{ Bed rest } & \multicolumn{2}{|c|}{ Plaster immobilisation } \\
\hline & Type & Duration & Type & $\begin{array}{l}\text { Duration } \\
\text { (months) }\end{array}$ \\
\hline Group I & $\begin{array}{l}\text { Localiser } \\
\text { jacket }\end{array}$ & $\begin{array}{l}1 \text { to } 3 \\
\text { months }\end{array}$ & $\begin{array}{l}\text { Localiser jacket } \\
\text { Milwaukee brace }\end{array}$ & $\left.\begin{array}{l}6 \\
6\end{array}\right\} 12$ \\
\hline Group II & $\begin{array}{l}\text { Plaster } \\
\text { shells }\end{array}$ & $\begin{array}{l}2 \text { to } 4 \\
\text { weeks }\end{array}$ & $\begin{array}{l}\text { Underarm plaster } \\
\text { jacket }\end{array}$ & 12 \\
\hline Group III & $\begin{array}{l}\text { Free in } \\
\text { bed }\end{array}$ & $\begin{array}{l}7 \text { to } 10 \\
\text { days }\end{array}$ & $\begin{array}{l}\text { Underarm plaster } \\
\text { jacket }\end{array}$ & $10^{*}$ \\
\hline
\end{tabular}

* the first 31 patients in this group wore the plaster jacket for 12 months

underarm plaster jacket was applied with the patient lying on the Risser plaster table but without traction. The plaster was carefully moulded over the iliac crests and rib hump to support the curve. The first 20 patients were kept in bed for at least four weeks but the last 33 patients were allowed up after two weeks. Activities until exploration were again confined to the house and garden.

Group III (106 patients). These patients were studied prospectively and all the spinal fusions and subsequent explorations performed by myself. As in Group II the scoliosis was corrected using the Harrington distraction system but without preliminary traction or the application of a Risser localiser jacket. The Moe (1958) interfacetal, intertransverse fusion technique was again used but in this group the posterior spinal elements were also thoroughly and deeply decorticated out to the tips of the transverse processes and a large number of fresh autogenous iliac bone grafts which had been cut into matchsticks were onlaid. After operation all patients were nursed free in bed for 7 to 10 days and then a simple well-moulded underarm plaster jacket was applied, as in Group II. They were then allowed home and encouraged to return to normal school and activities within a few weeks but were not allowed to participate in active sports.

At six months the patients in all three groups were readmitted to hospital where their plaster casts were removed and their spines explored. If solidly fused, the patients in Group I were placed in a Milwaukee brace for a further six months whereas patients in Groups II and III were replaced in their underarm plaster jackets. All of the patients in Group II and the first 31 patients in Group III wore an underarm jacket for an additional six months. Seventy-five of the more recent patients in Group III wore their jacket for only an additional four months.

\section{RESULTS}

Degree of correction. The number of degrees of correction and the percentage correction for the thoracic, thoracolumbar and lumbar curves in the three groups are shown in Tables III, IV and V. The greatest correction was obtained in Group III where the mean correction in the thoracic curves was 34 degrees (51 per cent), in the thoracolumbar curves 55 degrees (64 per cent), and in the lumbar curves 41 degrees ( 55 per cent). Patients with pseudarthroses. The findings at exploration of the fusion in the three groups are shown in Table VI. Seventy-four of the $\mathbf{4 0 6}$ patients were found to have pseudarthroses at one or more levels. The lowest incidence of pseudarthroses occurred in Group III (3.8 per cent) followed by Group II (15.8 per cent) and finally Group I ( 25 per cent).

To test for the significance between the success rates of the three groups, and also to allow for the possible effects of the different aetiologies of the curves, the proportions were fitted to a linear logistic curve using the method of maximum likelihood (Cox 1970). It was found that the improved incidence of solid fusions in Group III compared with Groups I and II was very highly significant. Although the success rate in Group II was greater than that in Group I this was not significantly better. The success rate in each group was independent of the aetiology of the curves.

Stability of the solid fusions. Having accurately diagnosed those patients with a pseudarthrosis it was then possible to study radiographically the remaining 332 patients whose spines were known to be solidly fused. These patients were followed for periods varying from 18 months to 15 years (mean 3 years 10 months). The types of curvature are described by the area of the spine in which the apex of the curve is located (Terminology Committee of the Scoliosis Research Society 1976).

The mean loss of correction in the solidly fused curves during the first year and at final follow-up for thoracic, thoracolumbar and lumbar curves are shown in Tables III, IV and V. The correction lost was calculated 
from the difference between the curvature shown on the supine spinal radiograph taken in the recovery room immediately after operation and that on the erect spinal radiograph taken at the time of follow-up. All curves were measured using the Cobb technique.

Group I curves, which were followed for an average of 4 years 10 months, had the greatest loss of correction: after the initial loss in the first year thoracic curves subsequently lost a mean of 6.4 degrees, thoracolumbar six degrees and lumbar eight degrees. These curves also took the longest time to stabilise.

Group II curves, which were followed for an average of three years two months, had a smaller loss of correction than Group I curves before becoming stable:

Table III. Loss of correction in solidly fused thoracic scoliosis (285 curves)

\begin{tabular}{|l|c|c|c|c|c|c|c|}
\hline & \multirow{2}{*}{$\begin{array}{c}\text { Number } \\
\text { of } \\
\text { curve } \\
\text { before } \\
\text { operation } \\
\text { curves }\end{array}$} & \multicolumn{2}{|c|}{$\begin{array}{c}\text { Mean correction } \\
\text { obtained }\end{array}$} & \multicolumn{3}{|c|}{$\begin{array}{c}\text { Mean loss of correction } \\
\text { (degrees) }\end{array}$} \\
\cline { 4 - 8 } & degrees) & Degrees & Per cent & $\begin{array}{c}\text { At } \\
\text { months }\end{array}$ & $\begin{array}{c}\text { At } \\
\text { 1 year }\end{array}$ & $\begin{array}{c}\text { Final } \\
\text { follow-up }\end{array}$ \\
\hline Group I & 149 & 60 & 23 & 39 & 4.0 & 7.6 & 14.0 \\
Group II & 42 & 84 & 36 & 46 & 5.0 & 6.2 & 9.3 \\
Group III & 94 & 70 & 34 & 51 & 2.4 & 3.1 & 3.9 \\
\hline
\end{tabular}

Table IV. Loss of correction in solidly fused thoracolumbar scoliosis (49 curves)

\begin{tabular}{|l|c|c|c|c|c|c|c|}
\hline & \multirow{2}{*}{$\begin{array}{c}\text { Number } \\
\text { of }\end{array}$} & $\begin{array}{c}\text { Mean } \\
\text { curve } \\
\text { before } \\
\text { operation } \\
\text { curves }\end{array}$ & \multicolumn{2}{|c|}{$\begin{array}{c}\text { Mean correction } \\
\text { obtained }\end{array}$} & \multicolumn{3}{|c|}{$\begin{array}{c}\text { Mean loss of correction } \\
\text { (degrees) }\end{array}$} \\
\cline { 4 - 8 } & Degrees & Per cent & $\begin{array}{c}\text { At } \\
\text { months }\end{array}$ & $\begin{array}{c}\text { At } \\
\text { 1 year }\end{array}$ & $\begin{array}{c}\text { Final } \\
\text { follow-up }\end{array}$ \\
\hline Group I & 33 & 68 & 29 & 47 & 5.0 & 8.0 & 14.0 \\
Group II & 7 & 72 & 39 & 59 & 7.7 & 10.8 & 13.5 \\
Group III & 9 & 89 & 55 & 64 & 2.5 & 3.2 & 5.3 \\
\hline
\end{tabular}

Table V. Loss of correction in solidly fused lumbar scoliosis (20 curves)

\begin{tabular}{|l|c|c|c|c|c|c|c|}
\hline & \multirow{2}{*}{$\begin{array}{c}\text { Number } \\
\text { of }\end{array}$} & $\begin{array}{c}\text { Mean } \\
\text { curve } \\
\text { before } \\
\text { operation } \\
\text { curves }\end{array}$ & \multicolumn{2}{|c|}{$\begin{array}{c}\text { Mean correction } \\
\text { obtained }\end{array}$} & \multicolumn{3}{|c|}{$\begin{array}{c}\text { Mean loss of correction } \\
\text { (degrees) }\end{array}$} \\
\cline { 4 - 8 } & Degrees & Per cent & $\begin{array}{c}\text { At } \\
\text { months }\end{array}$ & $\begin{array}{c}\text { At } \\
\text { 1 year }\end{array}$ & $\begin{array}{c}\text { Final } \\
\text { follow-up }\end{array}$ \\
\hline Group I & 6 & 78 & 26 & 35 & 3.0 & 6.0 & 14.0 \\
Group II & 0 & - & - & - & - & - & - \\
Group III & 14 & 75 & 41 & 55 & 3.9 & 4.7 & 5.6 \\
\hline
\end{tabular}

Table VI. Findings at exploration of $\mathbf{4 0 6}$ posterior spinal fusions

\begin{tabular}{|l|c|c|c|c|c|c|}
\hline \multirow{2}{*}{$\begin{array}{c}\text { Aetiology } \\
\text { of } \\
\text { scoliosis }\end{array}$} & \multicolumn{2}{|c|}{ Group I } & \multicolumn{2}{c|}{ Group II } & \multicolumn{2}{c|}{ Group III } \\
\cline { 2 - 7 } & patients & $\begin{array}{c}\text { Patients with } \\
\text { pseudarthroses } \\
\text { (per cent) }\end{array}$ & $\begin{array}{c}\text { Number of } \\
\text { patients }\end{array}$ & $\begin{array}{c}\text { Patients with } \\
\text { pseudarthroses } \\
\text { (per cent) }\end{array}$ & $\begin{array}{c}\text { Number of } \\
\text { patients }\end{array}$ & $\begin{array}{c}\text { Patients with } \\
\text { pseudarthroses } \\
\text { (per cent) }\end{array}$ \\
\hline Idiopathic & 133 & $37(27.8)$ & 33 & $6(18.1)$ & 73 & $2(2.7)$ \\
Congenital & 64 & $13(20.3)$ & 9 & $0(0)$ & 25 & $2(8.0)$ \\
Neuropathic & 46 & $11(23.9)$ & 15 & $3(20.0)$ & 8 & $0(0)$ \\
\hline Total & 243 & $61(25.0)$ & 57 & $9(15.8)$ & 106 & $4(3.8)$ \\
\hline
\end{tabular}


after the losses of the first year thoracic curves lost a mean of 3.1 degrees and thoracolumbar curves 2.7 degrees. There were no lumbar curves.

Group III curves, which were followed for an average of two years two months, had the least loss of correction and all stabilised rapidly with no loss after 18 months. The mean loss of correction after the first year was no more than one degree in thoracic and lumbar curves: thoracolumbar curves lost just over two degrees.

\section{DISCUSSION}

Factors infuencing the incidence of pseudarthroses Method of correction. Harrington instrumentation is said to have helped lower the incidence of pseudarthroses by providing increased rigidity to the developing fusion. In nearly all series the pseudarthroses have been diagnosed radiographically but unfortunately radiographs of the deformed spine are often difficult to interpret. The presence of a Harrington rod may also prevent the rapid loss of correction which is often the only indication of a pseudarthrosis and this may remain unrecognised until the rod breaks due to continuing stress. In order to overcome these difficulties all of the spines in this investigation were surgically explored six months after the attempted fusion.

Group I and II curves were both fused using only the Moe (1958) interfacetal fusion technique but the method of correction was different (Table I). The incidence of pseudarthroses in Group $I$, where the curves were corrected in a Risser localiser jacket and the patient was kept in bed for one to three months, was 25 per cent compared with 15.8 per cent in Group II, where the patient was treated by Harrington instrumentation and mobilised in an underarm jacket at two weeks.

Moe (1958) found a 23 per cent incidence of pseudarthroses, diagnosed radiographically, in 130 patients with idiopathic scoliosis treated in a similar manner to the patients in Group I of my series. He later reported on a further 173 patients treated by Harrington instrumentation with a reduction in the incidence of pseudarthroses to 17 per cent (Moe and Valuska 1968).

Fusion technique. Harrington instrumentation and an underarm jacket were used in both Groups II and III but the technique of fusion was different (Table I). An interfacetal fusion was performed in each group, but the 106 patients in Group III had an additional total decortication of all the posterior spinal structures followed by an onlay of matchstick grafts of autogenous iliac bone. This resulted in a further significant decrease in the incidence of pseudarthroses from 16 per cent in Group II to 3.8 per cent in Group III.

Goldstein (1969) stated that total decortication followed by the addition of fresh autogenous cancellous bone grafts not only gave a lower incidence of pseudarthroses but also produced a fusion mass better able to withstand bending once all external support was removed. In his 80 patients with idiopathic scoliosis, the incidence of pseudarthrosis, diagnosed radiographically, was five per cent. The 73 patients with idiopathic scoliosis in Group III of my series were submitted to a very similar procedure to Goldstein's except that a more meticulous technique of interfacetal fusion was used, and at exploration the incidence of pseudarthrosis was three per cent. Erwin, Dickson and Harrington (1976) compared two large series of patients with idiopathic scoliosis corrected by Harrington instrumentation and treated with and without supplementary autogenous iliac bone grafts. They reported that the incidence of pseudarthrosis, diagnosed radiographically, was reduced from 4.3 per cent to 0.6 per cent by the addition of the supplementary bone.

Homogenous and heterogenous bone grafts have also been used in other series (Blount et al. 1958; Brown 1965; Donaldson et al. 1969; Dickson and Harrington 1973) but the results have been much less successful than with autogenous bone.

\section{Factors infuencing the stability of the solidly fused spine}

Postoperative management should aim to produce a solid fusion and prevent loss of correction while the fusion is maturing and gaining strength.

Bed rest. Opinion regarding the appropriate period of bed rest has varied considerably. From 1935 to 1964 Cobb kept all his patients with scoliosis in bed for nine months after operation-six months in a Risser turnbuckle jacket, followed by three months in an underarm jacket. In 1958 Risser and Norquist reported that walking in a Risser localiser plaster jacket was possible 7 to 10 days after operation without significant loss of correction or increase in the incidence of pseudarthrosis. Most surgeons, however, continued to keep their patients in bed for at least three months and Wilson, Levine and Doherty (1971) extended this period to six months, without improving their results.

Clinical experience and experimental studies have shown that early weight-bearing not only accelerates the rate of healing of fractures but also significantly improves the strength of the healing bone (Sarmiento $e t$ al. 1977). Theoretically the same principles should apply to the spine after fusion and the early transmission of weight-bearing forces should strengthen and increase the size of the fusion mass. The psychological advantages of decreasing the period of recumbency and the time in hospital are obvious. In 1973 Leider, Moe and Winter reported that since 1967 they had allowed their patients to walk in a Risser-Cotrel jacket 7 to 15 days after Harrington instrumentation with only slight loss in correction; in their opinion the type of cast used was the key to success. Erwin et al. (1976), however, considered the full Risser cast unnecessary and since 1970 have allowed their patients to walk 7 to 10 days after 
Harrington instrumentation in a simple underarm body cast, with even less loss of correction and a very low incidence of pseudarthroses.

This theory of early mobilisation was put into practice in the management of the patients in Group III who were allowed to walk 7 to 10 days after Harrington instrumentation in a well-fitting underarm jacket and returned to normal activities. In contrast, the patients in Group I were kept in bed in a localiser jacket for one to three months after which their activities were confined to the house and garden until six months after operation. The patients in Group II were treated in an intermediate manner; they were confined to bed for two to four weeks after Harrington instrumentation and then allowed home in an underarm plaster jacket and confined to the house and garden until six months after operation (Table II). Group III curves which were treated by early mobilisation had better maintenance of correction than the curves in Group II which were better than the curves in Group I (Tables III to V).

Type and duration of immobilisation in plaster. The time spent in a plaster jacket after spinal fusion has also varied. Ponseti and Friedman (1950) found that the rate of pseudarthrosis was not influenced by cast immobilisation for periods longer than five months. Erwin et al. (1976) found, however, that if the plaster jacket was removed at six months there was an increased loss of correction up to 12 months with only a minimal loss occurring subsequently. This loss of correction in an otherwise solid fusion was presumably due to the immaturity of the fusion and prompted them to extend the length of time in plaster to nine months.

The type and duration of external spinal support for the solidly fused curves in my series varied in each of the three groups (Table II). The greatest loss of correction in the first year occurred in Group I where the spine was supported by a Risser localiser jacket for six months followed by six months in a Milwaukee brace. Harrington instrumentation and an underarm jacket were used in both Groups II and III, but the time in plaster and the fusion technique were different. In Group II the jacket was maintained for one year whereas for the majority of patients in Group III it was removed after ten months. Despite this Group III curves maintained their correction better and this can only be attributed to a greater strength in the fusion due to the use of the supplementary bone grafts.

Fusion technique. External support was not used after the first year for any of the solidly fused curves. These curves then suffered further loss of correction due to bending of the immature fusion before finally becoming stable. The severity of this loss was different in each of the three groups but the majority of curves had stabilised by 18 months. Although the same fusion technique was used in Groups I and II, there was a better maintenance of correction in Group II curves and this can only be explained by the presence of the Harrington internal fixation. Harrington instrumentation was used in both Groups II and III but the fusion technique was different. Group III curves maintained their correction better, which can be attributed to a stronger and more rapidly maturing fusion.

The total loss of correction in Group III by the time the spines had stabilised was a mean of 3.9 degrees for thoracic, 5.3 degrees for thoracolumbar and 5.6 degrees for lumbar curves. This loss of correction is similar to that in two other series treated by Harrington instrumentation with supplementary autogenous iliac bone grafts and early mobilisation. Leider et al. (1973) studied 106 patients with idiopathic scoliosis followed for an average of 19 months with an overall loss of correction of five degrees. In the series of 177 patients with idiopathic scoliosis, followed for an average of two years by Erwin et al. (1976), the overall loss of correction was 4.3 degrees.

My conclusions therefore are as follows. Early mobilisation 7 to 10 days after Harrington instrumentation, and a return to normal activities in a well-moulded underarm plaster jacket, does not have a detrimental effect on the maintenance of correction and may possibly have a beneficial effect on the development of the fusion. Total decortication and an onlay of autogenous iliac bone grafts in addition to a Moe interfacetal fusion and Harrington instrumentation not only lowers the incidence of pseudarthroses but also creates a spinal fusion which rapidly becomes stable with only minimal loss of correction after removal of all external support at 10 months. With these more modern techniques routine diagnostic exploration of the spine is no longer necessary.

\section{REFERENCES}

Ashley RK. Pseudarthrosis in scoliosis. J Bone Joint Surg [Am] 1967;49-A:197-8.

Blount WP. Schmidt AC, Keever ED, Leonard ET. The Milwaukee brace in the operative treatment of scoliosis. J Bone Joint Surg [Am] $1958 ; 40-A: 511-25$.

Brown NR. A review of 111 cases of surgical fusion. J Bone Joint Surg [Am] 1965;47-A:854

Cobb JR. Outline for the study of scoliosis. In: Instructional Course Lectures. The American Academy of Orthopaedic Surgeons. Ann Arbor: J. W. Edwards, 1948;5:261-75.

Cobb JR. Technique, after-treatment, and results of spine fusion for scoliosis. In: Instructional Course Lectures. The American Academy of Orthopaedic Surgeons. Ann Arbor: J. W. Edwards, 1952;9:65-70.

Cox DR. The analysis of binary data. London: Methuen, 1970.

Dickson JH, Harrington PR. The evolution of the Harrington instrumentation technique in scoliosis. J Bone Joint Surg [Am] 1973;55-A:993-1002. 
Donaldson WF, Wissinger HA, Stone CS. Exploration of scoliosis spine fusion. J Bone Joint Surg [Am] 1969;51-A:205.

Erwin WD, Dickson JH, Harrington PR. The postoperative management of scoliosis patients treated with Harrington instrumentation and fusion. J Bone Joint Surg [Am] 1976;58-A:479-82.

Goldstein LA. Treatment of idiopathic scoliosis by Harrington instrumentation and fusion with fresh autogenous iliac bone grafts. J Bone Joint Surg $[A m]$ 1969;51-A:209-22.

Graham JJ. Pseudarthrosis in scoliosis: routine exploration of forty-five operative cases. J Bone Joint Surg [Am] 1968;50-A:850.

James JIP. Correction and fusion for scoliosis. J Bone Joint Surg [Br] 1965;47-B:587-8.

Leider LL Jr, Moe JH, Winter RB. Early ambulation after the surgical treatment of idiopathic scoliosis. J Bone Joint Surg [Am] 1973;55-A:1003-15.

McMaster MJ, James JIP. Pseudarthrosis after spinal fusion for scoliosis. J Bone Joint Surg [Br] 1976;58-B:305-12.

Mathews RS, Stelling FH. Second look spinal exploration for scoliosis. J Bone Joint Surg [Am] 1970;52-A:409.

May VR, Mauck WR. Exploration of the spine following spinal fusion in the treatment of scoliosis. J Bone Joint Surg [Am] 1966;48-A:1449-50.

Moe JH. A critical analysis of methods of fusion for scoliosis. J Bone Joint Surg [Am] 1958;40-A:529-54.

Moe JH, Valuska JW. Evaluation of treatment of scoliosis by Harrington instrumentation. J Bone Joint Surg [Am] 1968;50-A:848-9.

Outland T, McDowell C, Fynn JC. Routine exploration of the fusion mass in the surgical treatment of scoliosis. J Bone Joint Surg [Am] 1964;46-A:1364-5

Ponseti IV, Friedman B. Changes in the scoliotic after fusion. J Bone Joint Surg [Am] 1950;32-A:751-66.

Risser JC, Norquist DM. A follow-up study of the treatment of scoliosis. J Bone Joint Surg [Am] 1958;40-A:555-69.

Sarmiento A, Schaefter JF, Beckerman L, Latta LL, Enis JE. Fracture healing in rat femora as affected by functional weight-bearing.J Bone Joint Surg $[$ Am $]$ 1977;59-A:369-75.

Terminology Committee of the Scoliosis Research Society. A glossary of scoliosis terms. Spine 1976;1:57-8.

Wilson RL, Levine DB, Doherty JH. Surgical treatment of idiopathic scoliosis. Clin Orthop 1971;81:34-47. 